\title{
Evaluasi Instalasi Pengolahan Air Limbah Hotel X di Surabaya
}

\author{
Hutomo Dwi Prabowo dan Ipung Fitri Purwanti \\ Jurusan Teknik Lingkungan, Fakultas Teknik Sipil dan Perencanaan, Institut Teknologi Sepuluh Nopember (ITS) \\ Jl. Arief Rahman Hakim, Surabaya 60111 Indonesia \\ e-mail:purwanti@enviro.its.ac.id
}

\begin{abstract}
Abstrak- Hotel X merupakan salah satu hotel bintang 4 di Surabaya yang memiliki sarana pengolahan limbah cair dengan kualitas effluent belum memenuhi baku mutu Peraturan Gubernur Jawa Timur No. 72 tahun 2013. Berdasarkan hasil pelaporan pengujian kualitas effluent Instalasi Pengolahan Air Limbah (IPAL) Hotel X pada 11 Juni 2015 diketahui bahwa salah satu parameter kualitas effluent tidak memenuhi baku mutu. Parameter tersebut adalah COD dengan konsentrasi sebesar $71,684 \mathrm{mg} / \mathrm{l}$. Oleh karena itu perlu dilakukan evaluasi terhadap IPAL yang ada.

Unit yang dievaluasi terdiri dari bak ekualisasi, tangki aerasi, dan bak pengendap 2 dengan sistem activated sludge. Unit-unit ini dievaluasi terhadap efisiensi dan efektivitas masing-masing bangunan. Sampel yang diuji diambil dari influent dan effluent tiap bangunan untuk mengetahui tingkat penyisihan dari tiap bangunan.

Hasil evaluasi berupa perubahan fungsi unit, modifikasi unit, dan juga penambahan unit baru.yang direncanakan agar kualitas effluent IPAL Hotel $X$ memenuhi baku mutu. Biaya yang dibutuhkan untuk perencanaan sesuai hasil evaluasi adalah Rp. 297.960.000,-
\end{abstract}

Kata Kunci- Evaluasi, IPAL, Hotel, Tangki Aerasi

\section{PENDAHULUAN}

$\mathrm{H}$ OTEL X merupakan salah satu hotel bintang 4 di Surabaya yang memiliki sarana pengolahan limbah cair domestik sebagai bentuk perhatiannya kepada lingkungan dan sebagai upaya untuk memenuhi ijin lingkungan.

Namun berdasarkan survey pendahuluan yang dilakukan, didapatkan bahwa kualitas effluent unit pengolahan tersebut masih belum memenuhi baku mutu Peraturan Gubernur Jawa Timur No.72 tahun 2013. Berdasarkan pelaporan yang dibuat Hotel X kepada BLH Jatim pada bulan Juni 2015, diketahui bahwa salah satu parameter yang tidak memenuhi baku mutu yaitu COD dengan konsentrasi sebesar 71,684 mg/L dimana baku mutu sesuai Peraturan Gubernur Jawa Timur No.72 tahun 2013 yaitu 50 mg/L. Oleh karena itu perlu dilakukan evaluasi terhadap instalasi tersebut.

\section{METODE EVALUASI}

Evaluasi dilakukan dengan membandingkan kondisi eksisting dengan kondisi ideal dari objek perencanaan yaitu IPAL Hotel $X$. Berdasarkan hasil evaluasi, dilakukan perencanaan ulang unit IPAL sehingga diharapkan kualitas effluent IPAL Hotel X dapat memenuhi baku mutu.

\section{A. Ruang Lingkup}

Ruang lingkup evaluasi ini adalah:

1. IPAL hotel yang dievaluasi adalah IPAL Hotel $X$ yang berlokasi di Surabaya dan berada di pinggir sungai.

2. Unit IPAL Hotel $X$ yang dievaluasi meliputi Tangki Ekualisasi, Tangki Aerasi, Clarifier, dan Sludge Tank.

\section{B. Pengumpulan Data}

Data Primer yang digunakan dalam evaluasi ini meliputi data kualitas air limbah influent dan effluent dari tiap unit IPAL Hotel X. Parameter yang diukur adalah parameter COD, BOD, dan TSS. Sampel yang diuji diambil sebanyak 2 kali pada 6 titik yang dapat dilihat pada Gambar 1.2.

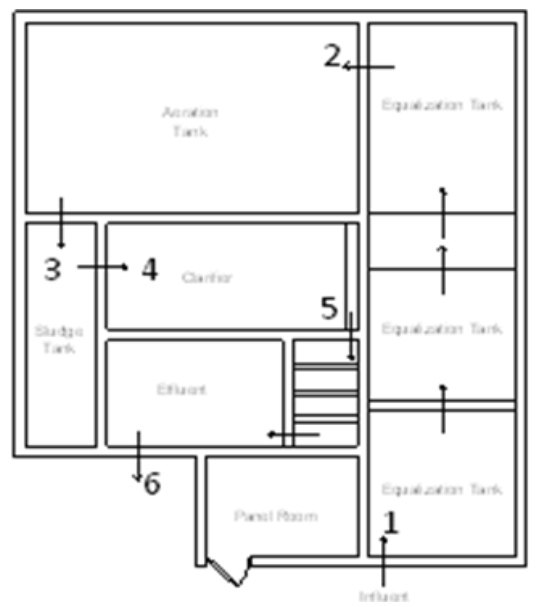

Gambar 1.2 Titik Pengambilan Sampel

Titik 1 merupakan influent tangki ekualisasi, titik 2 merupakan effluent tangki ekualisasi/ influent tangki aerasi, titik 3 merupakan effluent tangki aerasi/ influent sludge tank, titik 4 merupakan effluent tangki aerasi/ influent clarifier, titik 5 merupakan effluent clarifier, dan titik 6 merupakan effluent akhir IPAL.

Data sekunder yang digunakan adalah data okupansi Hotel $\mathrm{X}$ dan hasil pelaporan effluent IPAL Hotel X kepada Badan Lingkungan Hidup. 


\section{HASIL EVALUASI}

\section{A. Hasil Penelitian Pendahuluan}

\section{Debit Air Limbah}

Debit air limbah dihitung dari jumlah pemakaian kamar dan asumsi produksi air limbah. Hotel X memiliki 150 kamar dengan rata-rata okupansi $44 \%$ dengan tiap kamar diasumsikan terisi 2 orang. Menurut SNI Plambing Tahun 2005, hotel bintang 4 menggunakan air bersih sebanyak 300 liter/orang.hari. Kemudian diperkirakan $80 \%$ dari air bersih tersebut menjadi air kotor/ air limbah [3]. Berdasarkan hasil perhitungan didapatkan debit rata-rata adalah sebesar 32,02 $\mathrm{m}^{3} /$ hari dan debit maksimum adalah $72 \mathrm{~m}^{3} /$ hari.

\section{Kualitas Air Limbah}

Berdasarkan hasil analisa laboratorium terhadap sampel air limbah domestik yang diambil 1 minggu sekali pada influent dan effluent tiap unit IPAL, didapatkan rata-rata kualitas air limbah IPAL Hotel X seperti ditunjukkan pada Tabel 3.1:

Tabel 3.1

Hasil Analisa Kualitas Air Limbah

\begin{tabular}{ccccccc}
\hline Parameter & Titik & Titik & Titik & Titik & Titik & Titik \\
\hline $\begin{array}{c}\text { COD } \\
(\mathrm{mg} / \mathrm{L})\end{array}$ & 171,4 & 387,2 & 368,8 & 148,7 & 141,5 & 67,8 \\
$\begin{array}{c}\text { BOD } \\
(\mathrm{mg} / \mathrm{L})\end{array}$ & 53,64 & 61,5 & 167,6 & 99,69 & 39,28 & 30,99 \\
$\begin{array}{c}\mathrm{TSS} \\
(\mathrm{mg} / \mathrm{L})\end{array}$ & 245 & 115 & 145 & 120 & 55 & 55 \\
\hline
\end{tabular}

\section{B. Evaluasi IPAL}

Evaluasi dilakukan dengan membandingkan kondisi eksisting tiap bangunan terhadap kriteria desain yang meliputi kesesuaian fungsi unit, efisiensi penyisihan unit, dan kriteria desain spesifik tiap unit. Untuk melihat kesesuaian fungsi unit, dapat dilihat perbedaan antara denah IPAL berdasarkan perencanaan awal (Gambar 3.1) terhadap denah IPAL pada tahap operasional (Gambar 3.2). Berdasarkan kedua gambar tersebut tampak perbedaan jalannya aliran air dimana air dari tangki aerasi harusnya menuju clarifier namun pada tahap operasional air dari tangki aerasi justru menuju ke sludge tank lalu ke clarifier. Hal ini disebabkan karena saluran air dari tangki aerasi menuju clarifier tersumbat oleh adanya lumpur.

Adanya perbedaan arah aliran ini menyebabkan perubahan fungsi unit pada system secara keseluruhan. Salah satu unit yang terpengaruhi adalah unit Sludge Tank yang berdasarkan perencanaan digunakan untuk menampung activated sludge dari clarifier yang kemudian diaerasi dalam unit ini sebelum dikembalikan ke tangki aerasi sebagai return sludge. Dengan adanya perubahan aliran ini, tidak adanya return sludge dari Sludge Tank menyebabkan terganggunya kesetimbangan massa dalam pengolahan dan menyalahi konsep dasar pengolahan biologis menggunakan tangki aerasi dimana harus terjadi pengembalian activated sludge sebesar 25\%-50\% [2].

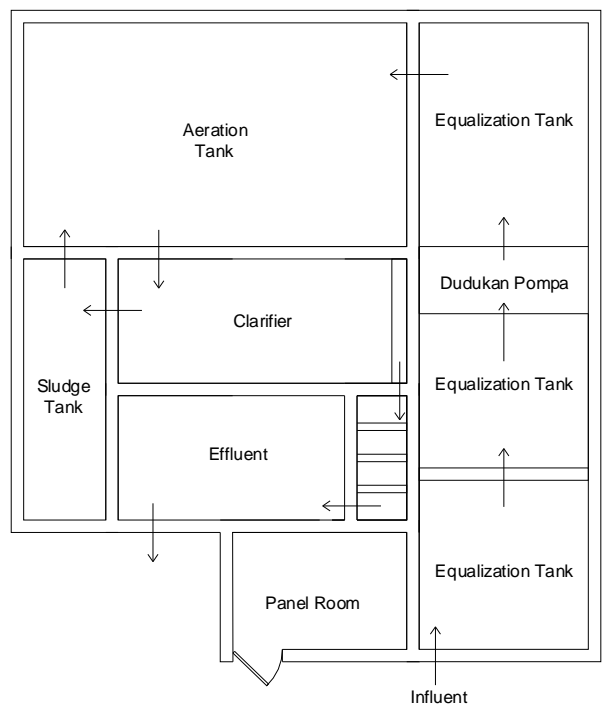

Gambar 3.1 Denah IPAL berdasarkan Perencanaan

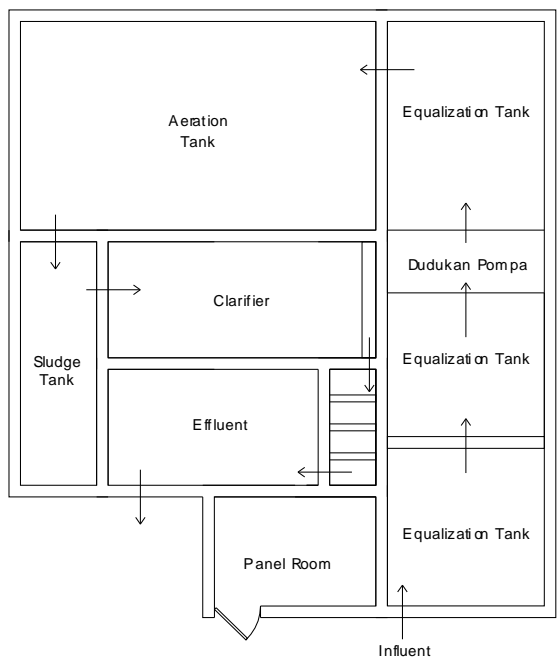

Gambar 3.2 Denah IPAL pada Tahap Operasional

Untuk efisiensi penyisihan unit dihitung dari hasil penelitian pendahuluan dimana dihitung selisih konsentrasi pencemar dari inlet bangunan dan outlet bangunan. Hasil efisiensi penyisihan tiap unit ditampilkan dalam Tabel 3.2.

Tabel 3.2

Efisiensi Penyisihan Unit IPAL

\begin{tabular}{lllll}
\hline \multirow{2}{*}{ Parameter } & $\begin{array}{l}\text { Bak } \\
\text { Ekualisasi }\end{array}$ & $\begin{array}{l}\text { Pengolahan } \\
\text { Biologis }\end{array}$ & $\begin{array}{l}\text { Bak } \\
\text { Effluent }\end{array}$ & $\begin{array}{l}\text { Efisiensi } \\
\text { Keseluruhan }\end{array}$ \\
\hline COD & $-126 \%$ & $63 \%$ & $52 \%$ & $60 \%$ \\
BOD & $-15 \%$ & $36 \%$ & $21 \%$ & $40 \%$ \\
TSS & $51 \%$ & $54 \%$ & $0 \%$ & $78 \%$ \\
\hline
\end{tabular}

Berdasarkan Tabel 3.2 dapat diketahui bahwa efisiensi penyisihan pengolahan biologis terbilang cukup rendah jika dibanding efisiensi penyisihan pengolahan bilogis menggunakan tangki aerasi sesuai kriteria desain yakni dalam rentang $85 \%$ $95 \%[1]$. 
Untuk kesesuaian kriteria desain spesifik tiap unit dilakukan perhitungan terhadap tiap unit lalu dibandingkan dengan kriteria desain. Berikut merupakan evaluasi spesifik tiap unit:

\section{Bak Ekualisasi}

Berdasarkan hasil perhitungan, didapatkan waktu detensi dalam bak ekualisasi yaitu 37,57 jam. Kriteria desain untuk waktu detensi bak ekualisasi adalah 4-8 jam [1]. Pada bak ekualisasi tidak ditujukan untuk menjadi unit pengendapan, oleh sebab itu unit ini direncanakan ulang.

\section{Pengolahan Biologis Tangki Aerasi}

Kriteria desain untuk tangki aerasi meliputi F/M ratio $(0,2-$ $0,4)$, Sludge Retention Time (5-15 hari), Organic Loading Rate $\left(0,4-1 \mathrm{~m}^{3} / \mathrm{m}^{2}\right.$.hari), Hydraulic Retention Time (3-10 jam), dan rasio resirkulasi $(25 \%$ - 50\%) [2]. Berdasarkan hasil perhitungan, terdapat beberapa parameter yang tidak sesuai dengan kriteria desain yang meliputi Hydraulic Retention Time, Organic Loading Rate, dan juga tidak adanya resirkulasi. Oleh sebab itu, perlu dilakukan perencanaan ulang terhadap unit ini.

\section{Pengolahan Biologis Clarifier}

Kriteria desain untuk clarifier meliputi Solid Loading Rate (4-6 $\mathrm{kg} / \mathrm{m}^{2}$.hari) dan Surface Overflow Rate (16-28 $\mathrm{m}^{3} / \mathrm{m}^{2}$.hari) [2]. Berdasarkan hasil perhitungan, dua parameter tersebut tidak sesuai dengan kriteria desain sehingga perlu dilakukan perencanaan ulang terhadap unit ini.

\section{Perencanaan Ulang IPAL}

\section{Bak Ekualisasi}

Direncanakan modifikasi Bak Ekualisasi dengan mendesain kompartemen 1 sebagai bak pengumpul, kompartemen 2 sebagai bak ekualisasi, dan kompartemen 3 untuk menjadi Bak Pengendap I. Berdasarkan hasil perhitungan, didapatkan dimensi perencanaan ulang dari bak ekualisasi.

\section{a. Bak Pengumpul}

Dalam Bak Pengumpul dipasang pompa untuk memompa air dari bak pengumpul menuju ke Bak Ekualisasi agar debit pengolahan tidak mengikuti fluktuasi debit yang ada. Berikut merupakan dimensi bak pengumpul:

- Panjang =3,5 meter

- Lebar = 3,4 meter

- Kedalaman $=3$ meter

b. Perhitungan Bak Ekualisasi

Bak Ekualisasi direncanakan menggunakan dimensi Kompartemen 2 dengan dimensi sebagai berikut:

- Panjang =3,1 meter

- Lebar =3,4 meter

- Kedalaman $=3$ meter

Jika menggunakan dimensi asli kompartemen 2, waktu detensi dari Bak Ekualisasi akan menjadi terlalu besar sehingga dimodifikasi kedalamannya menjadi 1 meter saja meskipun kriteria desain kedalaman bak ekualisasi adalah 1,5- 2 meter. Berikut merupakan perhitungan Bak Ekualisasi dengan dimensi yang baru:

Panjang $=3,1$ meter
Lebar $\quad=3,4$ meter

Kedalaman $=1$ meter (direncanakan)

Volume $=\mathrm{P} \times \mathrm{L} \times \mathrm{H}$

$$
=3,1 \times 3,4 \times 1
$$$$
=10,54 \mathrm{~m}^{3}
$$

$\mathrm{Q}$ ave $\quad=32,02 \mathrm{~m}^{3} / \mathrm{hari}=1,334 \mathrm{~m}^{3} / \mathrm{jam}$

$\mathrm{Td} \quad=$ Volume $/ \mathrm{Q}$ ave

$=10,54 \mathrm{~m}^{3} / 1,334 \mathrm{~m}^{3} / \mathrm{jam}$

$=7,9$ jam (memenuhi)

c. Perhitungan Bak Pengendap 1

Bak pengendap 1 direncanakan menggunakan dimensi Kompartemen 3 dengan dimensi sebagai berikut:

- Panjang =4,5 meter

- Lebar =3,4 meter

- Kedalaman $=3$ meter

Direncanakan dibuat 2 buah bak pengendap 1 yang akan digunakan secara bergantian ketika salah satu bak sedang dalam pengurasan dengan dimensi masing-masing bak pengendap 1 sebagai berikut:

$\begin{array}{ll}\text { - } \text { Panjang } & =3 \text { meter } \\ \text { - Lebar } & =1,5 \text { meter } \\ \text { - Kedalaman Air } & =1 \text { meter }\end{array}$

- Kedalaman Lumpur $=2$ meter

Dengan demikian, terdapat perubahan bentuk dari unit bak ekualisasi yang ditampilkan dalam Gambar 3.3 yang merupakan sketsa modifikasi bak ekualisasi.

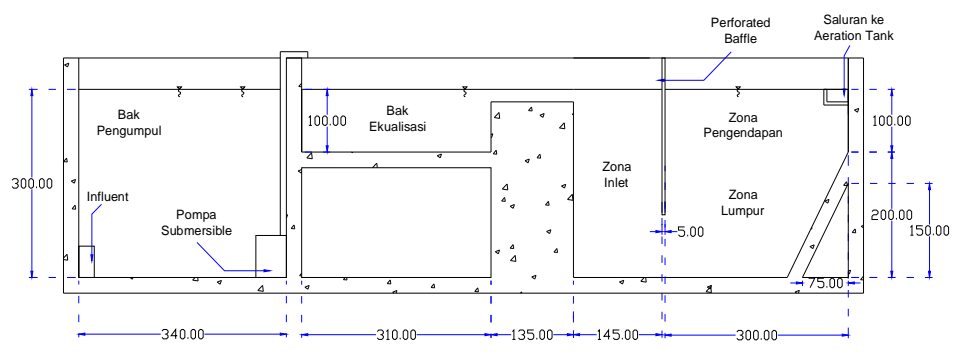

Gambar 3.3 Sketsa Modifikasi Bak Ekualisasi

\section{Pengolahan Biologis Tangki Aerasi}

Perencanaan ulang dilakukan dengan mengganti dimensi unit Tangki Aerasi dengan ukuran yang lebih kecil agar waktu detensi tidak terlalu besar, merencanakan sistem resirkulasi lumpur dan memasang sistem aerasi yang baru. Aeration tank menggunakan clarifier tank yang sudah ada. Berikut merupakan dimensi tangki aerasi sesuai perencanaan ulang:

- Panjang $=3,1$ meter

- Lebar =3,4 meter

- Kedalaman $=3$ meter

Dalam sistem aerasi yang menggunakan activated sludge, ada beberapa tipe aerasi yang dapat digunakan, yaitu bubble aeration, mechanical aeration, dan air sparging. Prinsip dasar dari sistem aerasi adalah kemampuan mentransfer oksigen ke dalam cairan pada puncak kebutuhan oksigen yang dapat disebut juga sebagai kebutuhan berat oksigen per volume per waktu $\left(\mathrm{kg} 0^{2} / \mathrm{m}^{3}\right.$.waktu) [4]. Untuk memenuhi kebutuhan 
oksigen, ditambahkan blower baru dengan kapasitas transfer oksigen sebesar $120 \mathrm{~L} /$ menit.

\section{Pengolahan Biologis Clarifier}

Perencanaan ulang dilakukan dengan memanfaatkan sekat antara tangki aerasi dengan clarifier. Selain itu, direncanakan juga sistem resirkulasi lumpur dengan menggunakan pompa yang juga berfungsi untuk memompakan lumpur untuk dibuang ke sludge drying bed. Berikut merupakan dimensi clarifier sesuai hasil perhitungan:

- Panjang $=2$ meter

- Lebar = 1 meter

- Kedalaman $=3$ meter

\section{Sludge Drying Bed}

Dalam sistem IPAL pada tahap operasional, tidak adanya pengolahan lumpur menyebabkan tidak ada proses pembuangan lumpur sehingga perlu ditambahkan unit sludge drying bed sebagai unit pengolahan lumpur. Pembuangan lumpur ke sludge drying bed dilakukan 1 hari sekali dengan daya tampung tiap bed adala untuk 5 hari. Lama pengeringan di tiap bed adalah 10 hari, sehingga didaptkan dimensi dari tiap sludge drying adalah sebagai berikut:

- Panjang Bed = 3,2 meter

- Lebar Bed = 1,1 meter

- Kedalaman Bed

$=\mathrm{h}$ lumpur $+\mathrm{h}$ pasir $+\mathrm{h}$ kerikil + freeboard

$=1 \mathrm{~m}$

Dengan adanya perencanaan ulang yang dilakukan, maka terdapat perubahan denah IPAL Hotel $\mathrm{X}$ yang ditampilkan dalam Gambar 4.1

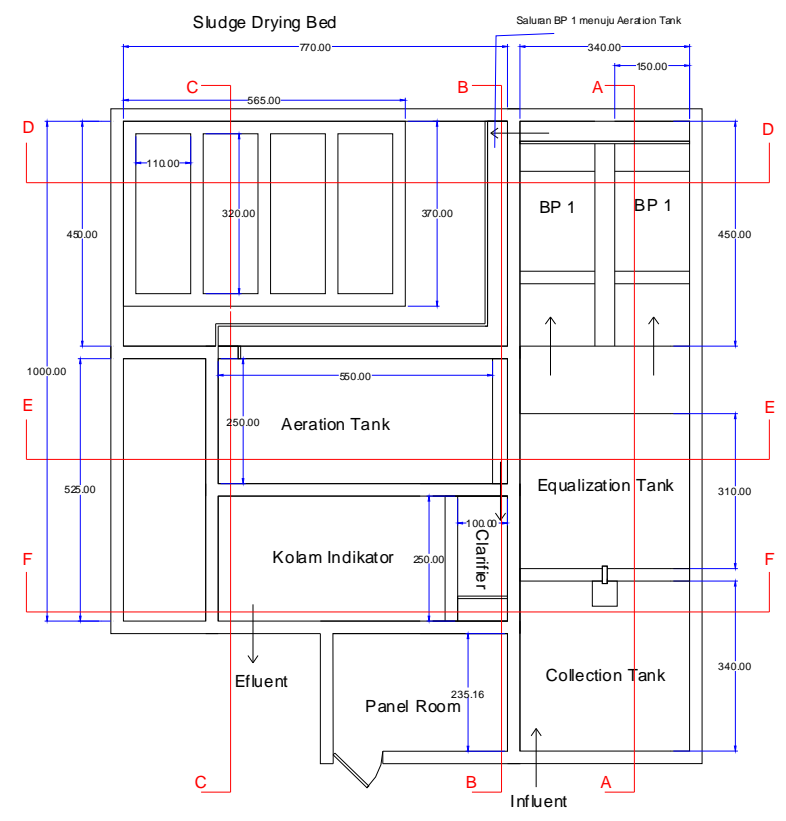

Gambar 4.1 Denah Perencanaan Ulang IPAL Hotel X

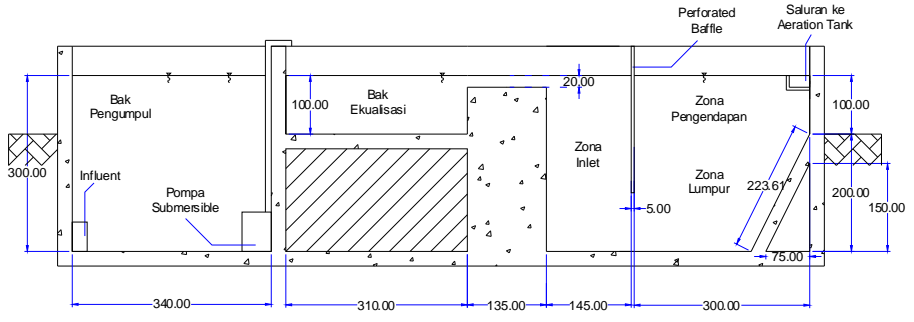

Potongan A - A

Gambar 4.2 Potongan A - A Perencanaan Ulang IPAL Hotel X

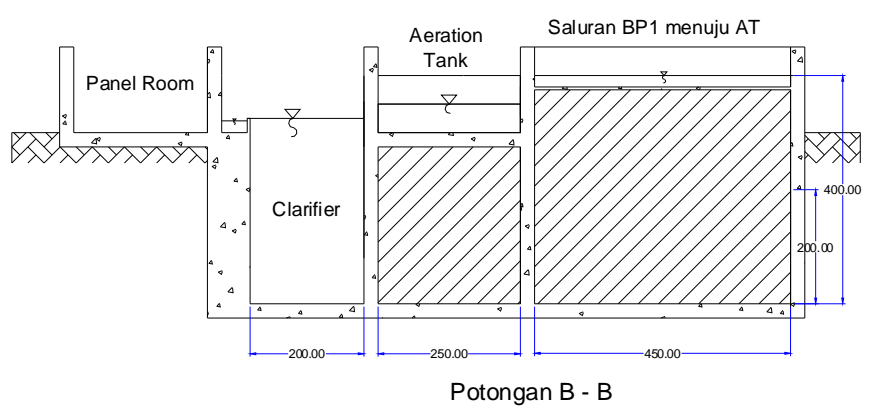

Gambar 4.3 Potongan B - B Perencanaan Ulang IPAL Hotel X

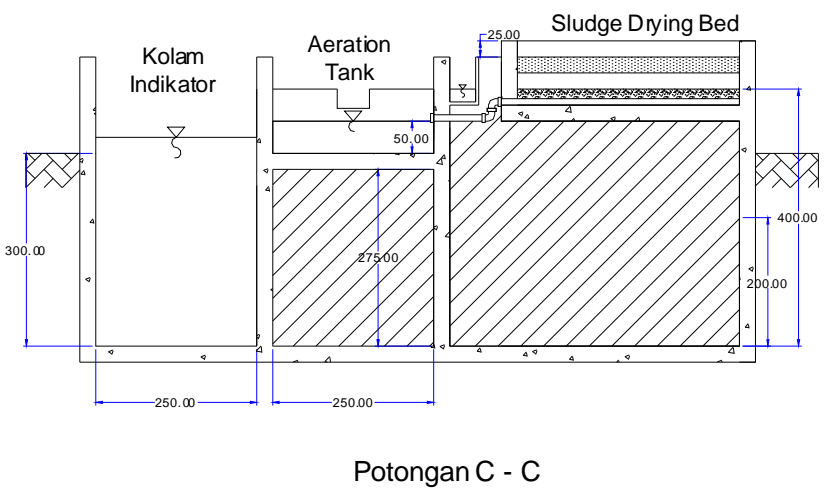

Gambar 4.4 Potongan C - C Perencanaan Ulang IPAL Hotel X

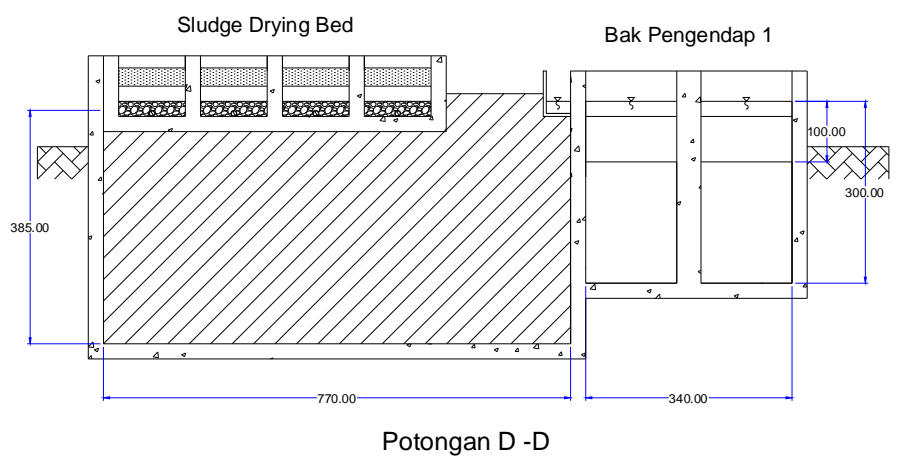

Gambar 4.5 Potongan D - D Perencanaan Ulang IPAL Hotel X 


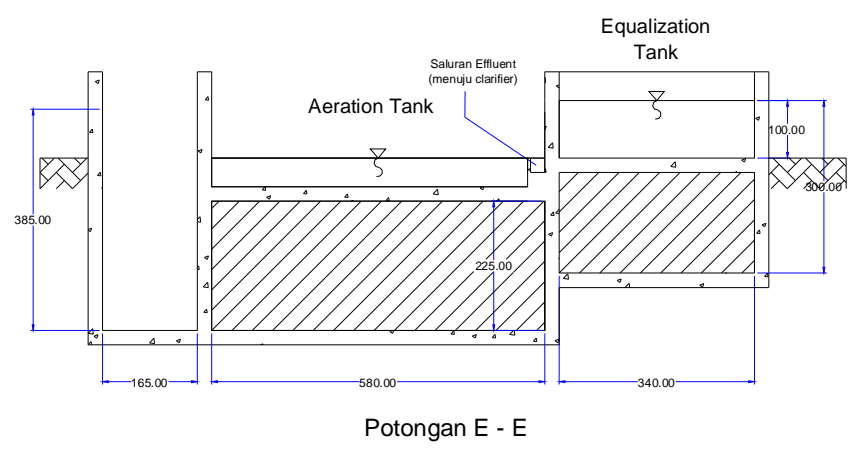

Gambar 4.6 Potongan E - E Perencanaan Ulang IPAL Hotel X

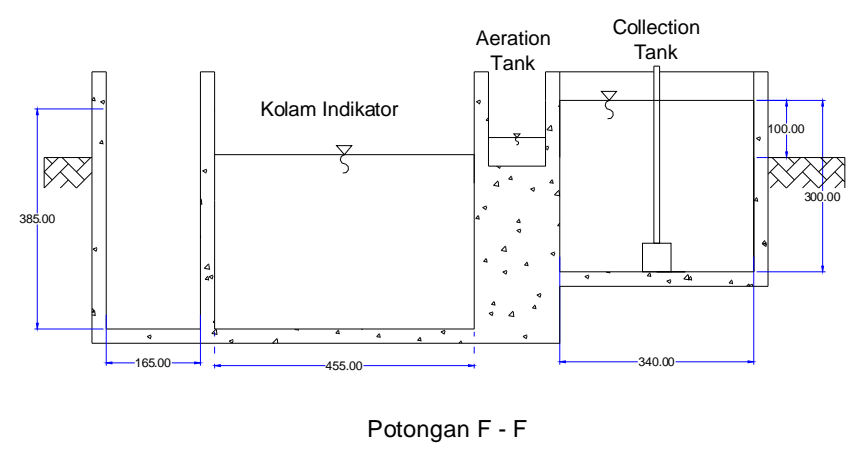

Gambar 4.7 Potongan F - F Perencanaan Ulang IPAL Hotel X

\section{RANCANGAN ANGGARAN BIAYA}

Perencanaan ulang sebagai hasil evaluasi IPAL Hotel $\mathrm{X}$ memerlukan biaya untuk penerapannya. Dalam melakukan perhitungan untuk rancangan anggaran biaya digunakan acuan yaitu HSPK (harga satuan pokok pekerjaan) Kota Surabaya Tahun 2015 dan dikalikan dengan volume pekerjaan sehingga didapatkan rancangan anggaran biaya untuk renovasi IPAL. Rancangan anggaran biaya dapat dilihat pada Tabel 4.1

Tabel 4.1.

Rancangan Anggaran Biaya

\begin{tabular}{|c|c|c|c|c|c|}
\hline No & Tahapan Pekerjaan & Kebutuhan & Satuan & \multicolumn{2}{|c|}{ Total Biaya } \\
\hline $\mathrm{I}$ & Penggalian Tanah Lumpur & 193.98 & $\mathrm{~m} 3$ & Rp & $26,983,862.25$ \\
\hline II & $\begin{array}{l}\text { Pengangkutan Lumpur dari Lubang Galian } \\
\text { Dalamnya Lebih Dari Im }\end{array}$ & 193.98 & $\mathrm{~m} 3$ & Rp & 5,717,413.13 \\
\hline III & Pembongkaran Beton & 11.82 & $\mathrm{~m} 3$ & Rp & $5,945,308.00$ \\
\hline IV & Pengurugan Tanah dan Pemadatan & 191.36 & $\mathrm{~m} 3$ & Rp & $36,201,011.85$ \\
\hline $\mathrm{v}$ & Pekerjaan Plat Lantai Beton & 22.10 & $\mathrm{~m} 3$ & Rp & $69,939,924.63$ \\
\hline VI & Pekerjaan Beton K & 7.54 & $\mathrm{~m} 3$ & Rp & $8,656,944.20$ \\
\hline VII & $\begin{array}{l}\text { Pekerjaan Balok Beton Bertulang }(200 \mathrm{Kg} \text { besi + } \\
\text { Bekisting) }\end{array}$ & 0.55 & $\mathrm{~m} 3$ & Rp & $3,916,291.50$ \\
\hline VIII & $\begin{array}{l}\text { Pekerjaan Kolom Beton Bertulang (150Kg besi } \\
\text { + Bekisting) }\end{array}$ & 0.16 & $\mathrm{~m} 3$ & Rp & $958,169.84$ \\
\hline IX & $\begin{array}{l}\text { Pekerjaan Dinding Beton Bertulang (200Kg } \\
\text { besi+ Bekisting) }\end{array}$ & 16.95 & $\mathrm{~m} 3$ & Rp & $111,428,952.53$ \\
\hline $\mathrm{x}$ & Pembersihan Lapangan "Ringan" dan Perataan & 119.84 & $\mathrm{~m} 2$ & $\mathrm{Rp}$ & $1,132,488.00$ \\
\hline & JUI & $\begin{array}{r}\text { H TOTAL + } \\
\text { PE }\end{array}$ & $\begin{array}{l}\text { H TOTAL } \\
\text { PN } 10 \%) \\
\text { PN(10\%) } \\
\text { BULATAN }\end{array}$ & $\begin{array}{l}\mathrm{Rp} \\
\mathrm{Rp} \\
\mathrm{Rp} \\
\mathrm{Rp}\end{array}$ & $\begin{array}{r}270,880,365.92 \\
27,088,036.59 \\
297,968,402.51 \\
297,960,000\end{array}$ \\
\hline
\end{tabular}

Berdasarkan Tabel 4.1 dapat dilihat bahwa total biaya yang dibutuhkan untuk perencanaan ulang IPAL Hotel X adalah Rp 297.960.000,-

\section{KESIMPULAN}

1. Hasil evaluasi pada IPAL Hotel $X$ adalah adanya endapan lumpur di tiap bangunan yang menyebabkan berubahnya aliran air dan tidak berjalannya resirkulasi lumpur sehingga IPAL Hotel X tidak berjalan sesuai perencanaan yang menyebabkan kualitas effluent tidak memenuhi baku mutu.

2. Untuk meningkatkan efisiensi kinerja IPAL Hotel $X$ maka perlu dilakukan perencanaan ulang yang meliputi modifikasi Bak Ekualisasi dengan penambahan Bak Pengendap 1, perubahan dimensi Tangki Aerasi, perubahan dimensi Clarifier, dan penambahan unit Sludge Drying Bed.

3. Biaya yang dibutuhkan untuk perencanaan ulang IPAL Hotel X adalah Rp. 297.960.000,-

\section{DAFTAR PUSTAKA}

[1] Tchobanoglous, George, Stensel, H.David, Tsuchihashi, Ryujiro, Burton, Franklin. 2003. Wastewater Engineering Treatment and Reuse $4^{\text {th }}$ Edition. Singapore : Metcalf \& Eddy Mc Graw Hill Company.

[2] Tchobanoglous, George, Stensel, H.David, Tsuchihashi, Ryujiro, Burton, Franklin. 2014. Wastewater Engineering Treatment and Resource Revovery $5^{\text {th }}$ Edition. Singapore : Metcalf \& Eddy Mc Graw Hill Company.

[3] Noerbambang, Soufyan M. dan Morimura, Takeo. 1991. Perencanaan dan Pemeliharaan Sistem Plambing. Jakarta: Pradnya Paramita.

[4] Winkler, M.A. 1981. Biological Treatment of Waste-water. USA: Ellis Horwood Ltd. 